\title{
AMINO ACID SEQUENCE OF SERINE PROTEASE INHIBITOR CI-1 FROM BARLEY. HOMOLOGY WITH BARLEY INHIBITOR CI-2, POTATO INHIBITOR I, AND LEECH EGLIN
}

\author{
by \\ IB SVENDSEN \\ Carlsberg Laboratory, Department of Chemistry, \\ Gamle Carlsberg Vej 10, DK-2500 Copenhagen Valby \\ and \\ SIGURD BOISEN*) and JØRN HEJGAARD \\ Department of Biochemistry and Nutrition, \\ Technical University of Denmark, DK-2800 Lyngby \\ *) Present address: National Institute of Animal Science, \\ Rolighedsvej 25, DK-1958 Copenhagen V
}

Keywords: Hiproly barley, chymotrypsin inhibitor, subtilisin inhibitor

Three molecular forms of a protein inhibitor of chymotrypsin and microbial alkaline proteases have been isolated from Hiproly high-lysine barley.

Automated Edman degradation of one of these inhibitor preparations (CI-1C) resulted in the following amino acid sequence ( 77 residues in total): Tyr-Pro-Glu-Pro-Thr-Glu-Gly-Ser-Ile-Gly-Ala-Ser-Gly-Ala-Lys-Thr-SerTrp-Pro-Glu-Val-Val-Gly-Met-Ser-Ala-Glu-Lys-Ala-Lys-Glu-Ile-Ile-Leu-Arg-Asp-Lys-Pro-Asn-Ala-GIn-IleGlu-Val-Ile-Pro-Val-Asp-Ala-Met-Val-Pro-Leu-Asn-Phe-Asn-Pro-Asn-Arg-Val-Phe-Val-Leu-Val（His, Lys, Ala, Thr, Thr, Val, Ala, Glx, Val, Ser, Arg) Val-Gly.

The inhibitor (CI-1) is homologous with another barley inhibitor (CI-2), with potato inhibitor I and with the elastase-cathepsin $\mathrm{G}$ inhibitor eglin from the leech Hirudo medicinalis (30-50\% of the amino acid residues in identical positions). This established wfamily of cystine-independent inhibitors" also showed some sequence similarities with the cystine-free yeast proteinase $B$ inhibitors 1 and 2 . In the reactive site region homologies with the cystine-rich inhibitors of the "Kazal pancreas secretory inhibitor" and the "Streptomyces subtilisin inhibitor" families were observed.

\footnotetext{
Abbreviations: APNE $=\mathrm{N}$-acetyl-D,L-phenylalanine-2-naphtylester; $\mathrm{CI}-1$ and $\mathrm{CI}-2=$ chymotrypsin inhibitor 1 and 2 from barley (3); LIE = Leech inhibitor eglin (17); PI-I = potato inhibitor I (15); Polybrene = hexadimethrine bromide; PTH = phenylthiohydantoin; SDS = sodium dodecyl sulfate; THEED = N,N,N',N',tetrakis (2-hydroxyethyl)ethylenediamine; YIB = yeast inhibitor of protease B (11).
} 


\section{INTRODUCTION}

Barley grains contain two immunochemically distinct inhibitors of chymotrypsin and microbial subtilisin-like alkaline proteases $(3,5,13)$. The inhibitor content is about twenty fold increased in Hiproly high-lysine barley $(3,4)$ and the two inhibitors, called CI-1 and CI-2, have been obtained in a highly pure form from this source $(3,6)$. Recently, the amino acid sequence of a lysine-rich protein from barley was determined (19). This protein was identified as inhibitor CI-2 (20) and a high degree of homology with the well characterized potato inhibitor I (15) was demonstrated.

The purpose of the present paper is: 1) to describe further separation of barley inhibitor CI-1 into a number of molecular forms with different charge properties, 2) to present the amino acid sequence of one of these inhibitors, and 3) to discuss sequence homologies between the two barley inhibitors $\mathrm{CI}-1$ and $\mathrm{CI}-2$ and other serine protease inhibitors.

\section{MATERIALS AND METHODS}

\subsection{Materials}

Protease inhibitor CI-1, previous purified from Hiproly barley by successive use of ammonium sulfate fractionation, gel filtration and cation exchange chromatography (3) was used as starting material. Immunoelectrophoresis and isoelectric focusing showed that the CI-1 inhibitor was effectively separated from the CI-2 inhibitor, and non-active proteins could not be detected in the inhibitor preparation. The purified inhibitor was composed of at least 4 molecular forms with isoelectric points in the pH-range 4.5-5.5

All reagents used with the sequencer were from Pierce Eurochemie B.V., Rotterdam, Holland, except THEED which was obtained from ICN-K\&K Laboratories, Plainview, USA, ethylacetate from Merck, Darmstadt, West Germany, and heptane from Fluka, Buchs, Switzerland. APNE was purchased from Bachem, Bubendorf, Switzerland.

\subsection{Methods}

\subsubsection{Chromatography}

Anion exchange chromatography was perfor- med on a column of DEAE-Sephadex A-50 $(300 \times 15 \mathrm{~mm})$ equilibrated with $25 \mathrm{~mm}$-Tris $\mathrm{HCl}$, pH 7.5. About $170 \mathrm{mg}$ of barley CI-I inhibitor from previous purification steps (3) was applied in the same buffer. The column was washed with $100 \mathrm{ml}$ buffer before elution with a buffer gradient. Absorbance at $280 \mathrm{~nm}$ was measured continuously, $8 \mathrm{ml}$ fractions collected and chymotrypsin inhibitor activity determined. Relevant fractions were pooled, dialyzed and rechromatographed under the same experimental conditions in the presence of $6 \mathrm{M}$-urea.

\subsubsection{Electrophoresis}

Isoelectric focusing was made with $2 \%$ Ampholine, pH $3-10$, at $25^{\circ} \mathrm{C}$ in $74 \times 2.7 \mathrm{~mm}$ polyacrylamide gel rods, and staining for inhibitors of subtilisin was based on the chromogenic substrate APNE (5). SDS-polyacrylamide gel electrophoresis was made in $180 \times 180 \times 1 \mathrm{~mm}$ gel slabs as described previously $(3,20)$.

\subsubsection{Amino acid analysis}

The amino acid composition was determined after acid hydrolysis in $5.7 \mathrm{M}-\mathrm{HCl}$ in an evacuated and sealed tube at $110^{\circ} \mathrm{C}$ for 24 hours. The analysis was performed with a Durrum model 500 amino acid analyzer.

\subsubsection{Amino acid sequence determination}

Amino acid sequence determinations were made in a Beckman liquid phase sequencer, model $830 \mathrm{C}$, using the Beckman programme 122974. Instead of Quadrol, THEED was used in a $0.1 \mathrm{M}$-concentration (1). The PTH-amino acids were identified by HPLC using a linear gradient of methanol from $10 \%$ to $50 \%$. Additional information was obtained by thinlayer chromatography on polyamide sheets (9). When the $\mathrm{CNBr}$-peptides were sequenced, Polybrene was added to the cup in order to minimize loss of material in the extraction steps.

Digestion with carboxypeptidase $\mathrm{Y}$ was done as described by MARTIN et al. (12) with and without $0.5 \%$ SDS in the reaction mixture. 


\subsubsection{Acetylation and cyanogen bromide cleavage}

Acetylation was performed in $0.1 \mathrm{M}$ $\mathrm{NH}_{4} \mathrm{HCO}_{3}, \mathrm{pH} 8.0$, by addition of acetic anhydride $(4 \times 25 \mu \mathrm{l}$ with $20 \mathrm{~min}$ intervals $)$. Reaction mixture containing $1 \mathrm{mg}$ of inhibitor was freeze-dried and redissolved in $1 \mathrm{ml} 70 \%$ formic acid. $30 \mathrm{mg} \mathrm{CNBr}$ was added, and the reaction took place overnight in the dark at room temperature. The mixture was purged with a stream of nitrogen to remove excess of $\mathrm{CNBr}$ and placed directly in the sequencer cup.

\section{RESULTS}

\subsection{Preparation of inhibitors}

In order to separate the inhibitor forms for sequence studies, pooled material from SPSephadex cation exchange chromatography (3) was subjected to anion exchange chromatography on DEAE-Sephadex (Figure 1). One minor and three major inhibitor peaks were obtained after elution with a buffer gradient. Pooled material from each of the three major peaks (indicated by bars A, B, and C in Figure 1) was rechromatographed under the same experimental conditions, but in the presence of $6 \mathrm{~m}$-urea. Each of the three experiments resulted in elution of a symmetrical protein peak completely overlapping with the chymotrypsin inhibitor activity. Inhibitor preparations CI-1 A, B, and C eluted at the same salt concentration as in the first anion

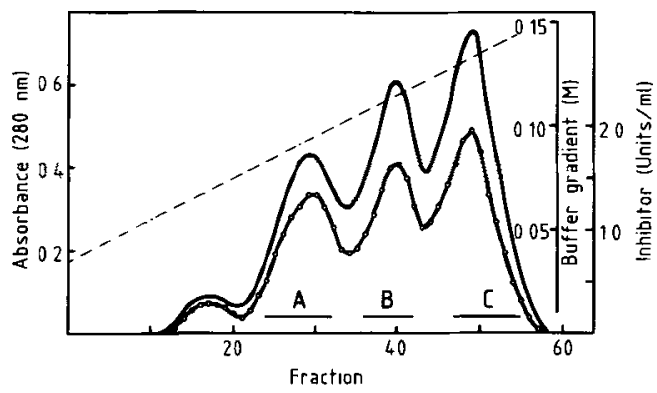

Figure 1. Separation of barley CI-1 inhibitors by anion exchange chromatography on DEAE-Sephadex A.50 at $\mathrm{pH} 7.5$.

- . . - buffer gradient; - absorbance at 180 $\mathrm{nm}$; -O-O-O-O- chymotrypsin inhibitor activity. Fractions 24-32 (CI-1A), 36-42 (CI-1B) and $47-55$ (CI-IC) were pooled as indicated by the bars.

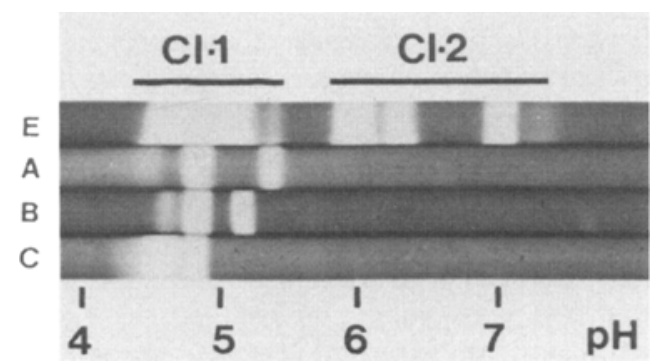

Figure 2. Isoelectric focusing of barley $\mathrm{CI}-1$ inhibitors.

About $0.7 \mu \mathrm{g}$ of each inhibitor preparation (A, $B$ and C) or Hiproly barley extract (E) corresponding to $0.5 \mathrm{mg}$ grain were applied. After isoelectric focusing the gel was stained for subtilisin inhibitor activity (5). A pH-scale and the isoelectric range of $\mathrm{Cl}-1$ and $\mathrm{CI}-2$ inhibitors $(3,5)$ are indicated on the figure.

exchange (cf. Figure 1), and apparently $6 \mathrm{M}$-urea did not affect the charge properties of the different inhibitors. Central peak fractions corresponding to $40-50 \%$ of the total activity were pooled, desalted and freeze dried.

The three inhibitor preparations were characterized by isoelectric focusing followed by specific staining for subtilisin inhibitor activity (Figure 2) and by SDS-gel electrophoresis (Figure 3). In contrast to the apparently well-

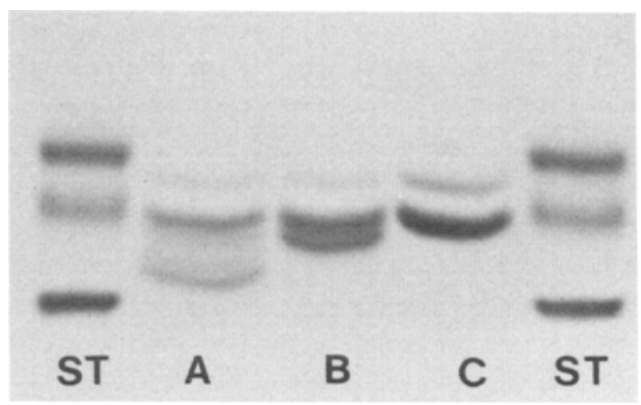

Figure 3. SDS-gel electrophoresis of barley CI-1 inhibitors.

About $5 \mu \mathrm{g}$ of each inhibitor preparation (A, B and C) were applied, and after electrophoresis the gel was stained for protein with Coomassie blue R-250. ST indicates application of the following standard proteins: cytochrome $\mathrm{C}(\mathrm{MW} \mathrm{13,000)}$, aprotinin (MW 6,500) and (bottom) glucagon (MW 3,500). 
defined fractions isolated by anion exchange (Figure 1), these analytical experiments showed that all inhibitor preparations were composed of two or more forms with different charge properties and molecular sizes. As discussed previously $(3,20)$, genetic variants, partially degraded $\mathrm{N}$-termini and molecular aggregation may explain these complex patterns. Rocket immunoelectrophoresis experiments (20) with monospecific antibodies (3) towards the two barley inhibitors CI- 1 and CI-2 confirmed that the CI-1 inhibitor preparations were not contaminated with inhibitor CI-2. No immunoelectrophoretic relationships with inhibitors in crude potato inhibitor preparations ( 20 ) were observed.

Inhibitor preparation CI-1C was selected for the sequence studies. This fraction represented the most acidic inhibitor zones in isoelectric focusing (Figure 2) and appeared to be the most homogeneous with respect to molecular size (Figure 3).

\subsection{Sequence determination of inhibitor $\mathrm{CI}-1 \mathrm{C}$}

The intact protein $(0.5 \mathrm{mg})$ was sequenced from the $\mathrm{N}$-terminus through 57 cycles with a repetitive yield of $96 \%$. Two chains were actually sequenced, one starting at $\mathrm{Tyr}(7)$ and another starting at Glu (9) (so numbered for comparison with other inhibitors, see Figure 4). The two chains were present in approximately equal amounts, thus a double check on the

10

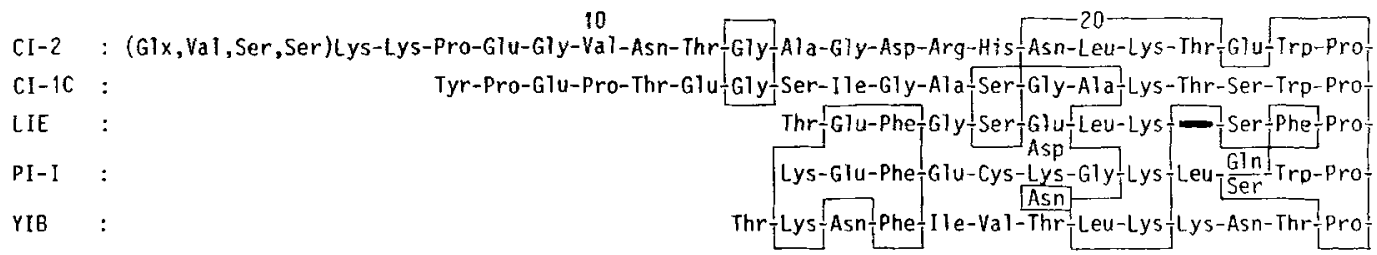

CI-2 : Glu-Leu-Val-Gly-Lys-Ser-Val-Glu-Glu-Ala-Lys LLs-Val-Ile-Leu-Gin-Asp-Lys-Pro-Glu-Ala-GIn-Ile-Ile

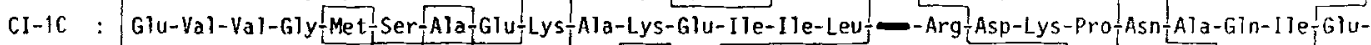
LIE : Glu-Val-Val-Gly-Lys Thr-Val-Asp-Gln-Ala Arg-Glu-Tyr-Phe-Thr--Leu-His-Tyr-Pro-Gln-Tyr-Asn-Val Tyr-

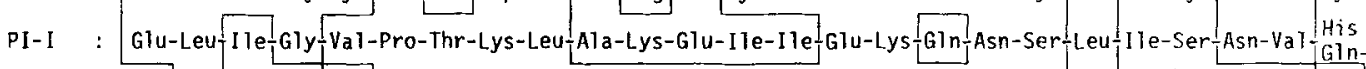

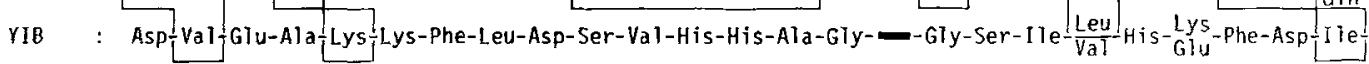

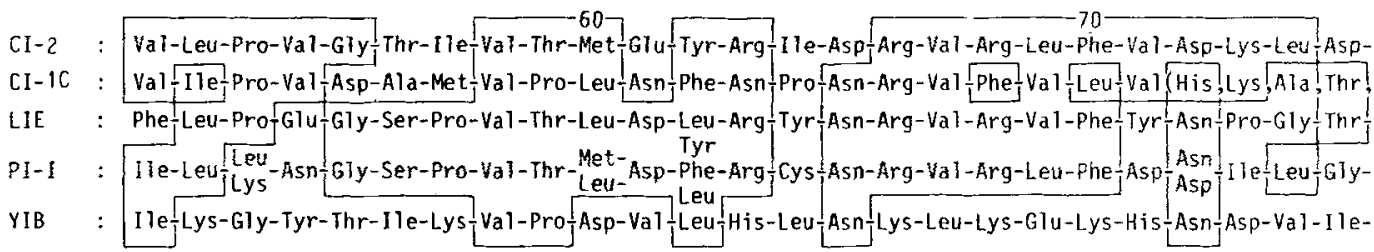

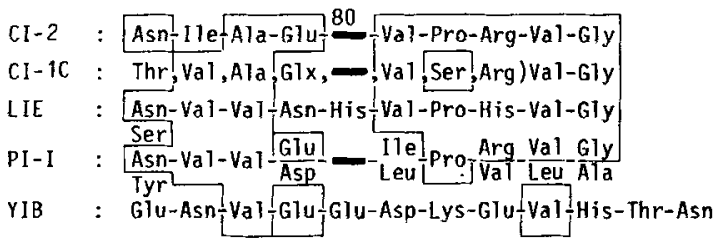

Figure 4. Amino acid sequence of barley inhibitor CI-1C.

Comparison with barley inhibitor CI-2 $(19,20)$, potato inhibitor I (PI-I, polymorphous sequence) (15), leech eglin (LIE) (17), and yeast protease B inhibitor (YIB, dimorphous sequence) (11). Homologous sequences are boxed. - indicate "gaps « introduced to obtain maximal homology among the inhibitors. The numbering refers to the sequence of the barley CI-2 inhibitor as used previously (20). 
individual steps in the sequencing was obtained.

Another $0.5 \mathrm{mg}$ sample was acetylated at the $\mathrm{N}$-terminus with acetic anhydride and then subjected to cleavage with $\mathrm{CNBr}$. After removal of the reagents in a stream of nitrogen the peptide mixture was placed directly in the sequencer cup together with Polybrene. Two sequences could be followed, one starting at Ser (31) and one at Val (58) as expected. Since the first sequence was known throughout, an unknown part of the second sequence was easily determined, and the total sequence was extended to include Val (71) (Figure 4). In several additional experiments with peptides obtained after tryptic or $\mathrm{CNBr}$ cleavage it was not possible to extend the sequence beyond $\mathrm{Val}(71)$.

Attempts to determine the C-terminal sequence by digestion with carboxypeptidase $\mathrm{Y}$ in the absence of SDS were not successful. This method also failed when inhibitor CI-2 (19) and leech eglin (17) were sequenced. If $0.5 \%$ SDS was present (12), however, inhibitor $\mathrm{CI}-1 \mathrm{C}$ as well as leech eglin (17) could be digested. Two residues were liberated from the barley CI-1C inhibitor; Gly followed by Val. Thus, the four homologous inhibitors belonging to the spotato inhibitor I family" (see section 3.3) have the same C-terminal sequence Val-Gly and, apparently, this terminal is buried and not directly accessible to degradation by carboxypeptidase. It therefore seems reasonable to presume that inhibitor CI-1 ends in the same position (residue 85 , Figure 4 ) as the three other inhibitors with a C-terminal glycine. If the results from amino acid analysis of the inhibitor CI-1C preparation were calculated on basis of this assumption, an amino acid composition of the C-terminal undecapeptide not sequenced could be obtained by difference (Table I). Tentatively, these amino acids could be lined up in a sequence showing a high degree of homology with the three other inhibitors (Figure 4). With the suggested amino acid composition (Table I) the $\mathrm{CI}-\mathrm{IC}$ inhibitor should contain 2 methionine residues. This result is in agreement with the presence of three peptides after $\mathrm{CNBr}$-cleavage.

Molecular weights of 8,000 and 8,300 were calculated for the two molecular forms present in the CI-1C preparation. Comparison with the SDS-gel electrophoresis results (Figure 3) suggests that both forms are present in the same
Table I

Amino acid composition of inhibitor preparation CI-1C.

\begin{tabular}{|c|c|c|c|}
\hline $\begin{array}{l}\text { Amino } \\
\text { acid }\end{array}$ & $\begin{array}{c}\text { residues }^{\text {a) }} \\
\text { per molecule }\end{array}$ & $\begin{array}{l}\text { residues }^{b} \text { ) } \\
\text { from } \\
\text { sequence }\end{array}$ & $\begin{array}{l}\text { differ- } \\
\text { ence }\end{array}$ \\
\hline Asx & $6.2(6)$ & 6 & \\
\hline Thr & $3.7(4)^{c)}$ & 2 & 2 \\
\hline Ser & $4.9(5)^{c)}$ & 4 & 1 \\
\hline Glx & $7.7(8)$ & 7 & 1 \\
\hline Pro & $6.7(7)$ & 7 & \\
\hline Gly & $4.7(5)$ & 5 & \\
\hline Ala & $8.4(8)$ & 6 & 2 \\
\hline Val & $10.8(11)^{d)}$ & 9 & 2 \\
\hline Met & $2.3(2)$ & 2 & \\
\hline Ile & $5.2(5)^{d)}$ & 5 & \\
\hline Leu & $3.4(3)$ & 3 & \\
\hline Tyr & $0.7(1)$ & 1 & \\
\hline Phe & $2.0(2)$ & 2 & \\
\hline His & $0.5(1)$ & 0 & 1 \\
\hline Lys & $4.5(5)$ & 4 & 1 \\
\hline Arg & $3.4(3)$ & 2 & 1 \\
\hline Trp & $1 \quad(1)^{e)}$ & 1 & \\
\hline Cys & $\left.0 \quad(0)^{e}\right)$ & 0 & \\
\hline $\begin{array}{l}\text { Total } \\
\text { residues }\end{array}$ & 77 & 66 & 11 \\
\hline
\end{tabular}

a) Hydrolysis time 24 hours. Calculations based on a Phe content of 2 residues per molecule. b) Data from Figure 4 residues $7-71$ and $84-85$. c) Extrapolated to zero-time based on previous analyses (13). d) Calculated on previous results from 72 hours hydrolysis (13). e) Result from previous analyses (3).

major protein band detected after electrophoresis of the $\mathrm{CI}-1 \mathrm{C}$ inhibitor preparation. Another protein corresponding to a slightly higher molecular weight was present in relatively high amounts in the inhibitor $\mathrm{Cl}-1 \mathrm{C}$ and apparently also in the two other inhibitor preparations $\mathrm{CI}-1 \mathrm{~A}$ and CI-1B (Figure 3). Previous experiments did not show the presence of non-active proteins in the inhibitor mixture used as starting material for the present study (3), and no wbackground" sequence from a contaminant protein was detected before or after cleavage with $\mathrm{CNBr}$. The most likely explanation seems to be that this protein zone represents an inhibitor form with a blocked N-terminus, in accordance with results obtained during sequencing of barley inhibitor CI-2 (19). 
In further analogy with the »ragged $\mathrm{N}$ terminus found in the CI-2 inhibitor and other inhibitors $(15,19,20)$, the proteins with lower molecular weights found in the CI-1 A and CI-1B inhibitor preparations (Figure 3) may correspond to molecular forms with more degraded N-termini.

\subsection{Comparison of sequences}

Homology between barley inhibitor CI-2 and potato inhibitor I has been demonstrated previously (20) and, recently, an elastase-cathepsin G inhibitor (called eglin) from the leech Hirudo medicinalis was also found to be homologous with the potato inhibitor (18). Obviously the barley inhibitor $\mathrm{CI}-\mathrm{I}$ belongs to the same winhibitor family « (Figure 4). In addition to the identical C-terminal -Val(84)-Gly(85) discussed above, a high degree of homology between the four inhibitors was found in the stretch of 57 residues (residue 14-71, Figure 4), where the sequence of all four inhibitors has been determined. To obtain maximal homology, one deletion in the leech inhibitor sequence (residue 22) and one insertion in the potato inhibitor sequence Lys (41) had to be introduced. Comparison of amino acids in identical positions in these four inhibitors (Table II) showed between $30 \%$ and $46 \%$ homology in the sequence of residues 1471. However, it is impossible from such a comparison to suggest which of the two inhibitors originates from the same monocotyledonous plant species, which one is from a dicotyledonous plant, and which is the inhibitor originating from a primitive invertebrate animal. Apparently, these inhibitors diverged from one

\section{Table II}

Homology between different inhibitors. Amino acids in identical positions in the sequence of residues 14 to 71 (see Figure 4).

\begin{tabular}{lcccc}
\hline & \multicolumn{4}{c}{ \% Homology } \\
Inhibitors & YIB & LIE & PI-I & CI-2 \\
compared & & & & \\
\hline CI-1 & 11 & 32 & 30 & 46 \\
CI-2 & 11 & 35 & 40 & \\
PI-I & 16 & 46 & & \\
LIE & 16 & & & \\
\hline
\end{tabular}

another very early during evolution, and thus a wide distribution in plants and animals of homologous inhibitors belonging to the same family may be expected.

All four inhibitors inactivate chymotrypsin and subtilisins. The reactive site $\left(\mathrm{P}_{1}-\mathrm{P}^{\prime}{ }_{1}\right)$ of the potato inhibitor and the leech inhibitor have been identified as Met/Leu(60)-Asp(61), using the numbering of the present paper. The presence of Leu(60)-Asn(61) and Met(60)-Glu(61) bonds in the two barley inhititors is in accordance herewith.

In contrast to the three other inhibitors, the potato inhibitor also inactivates trypsin. Treatment of the potato inhibitor with catalytic amounts of trypsin suggested two major and two minor cleavage sites (all different from the chymotrypsin inhibitory site) as potential trypsin binding sites (16). One of the sites suggested was between Lys(41)-Gln(42) and, if this is the true binding site, the insertion of Lys(41) resulting in an extention of the peptide chain with one residue may explain that the potato inhibitor I, but not the barley inhibitor CI-1 with $\operatorname{Arg}(41 / 42)$ in the same position, inhibits trypsin.

The conservation of all intra-chain disulfide bridges has been observed within different inhibitor families and, especially, the localization of the reactive site in a disulfide loop has been considered essential (10). A characteristic property of the two barley inhibitors and the leech inhibitor is the absence of cystine residues. Recently, it has been demonstrated that carboxymethylation of the two cysteines forming the only disulfide bridge present in the potato inhibitor had no effect on the inhibitory properties (14). Obviously, the inhibitor family here established should be classified among families where stabilization of the reactive site tertiary structure is only dependent on non-covalent forces.

Among the few other cysteine-free protease inhibitors hitherto known only yeast inhibitors of the two endogenous proteases $\mathrm{A}$ and $\mathrm{B}$ have similar peptide lengths of about 70 residues $(2$. 11). Of these inhibitors the two proteinase B isoinhibitors 1 and 2 show a clear similarity with the four members of the "potato inhibitor I family«. Recent studies suggested that yeast protease B has a "mixed typer specificity 
corresponding to that of porcine chymotrypsin C as well as trypsin (8), but the reactive site(s) of the endogenous inhibitor has not been identified. In the sequence of 57 residues discussed above, an 11-16\% homology of the yeast inhibitor with the four other inhibitors was observed (Figure 4, Table II). Generally, this degree of homology is not sufficient to suggest a divergent evolution. It should, however, be noted that the two genetic variants of the yeast protease B inhibitor could be aligned with the four other inhibitors without introduction of new insertions or deletions, and the homology is significantly connected with the conservative positions of the four inhibitors, but not especially confined to the active site region. Thus, Lys(21), Pro(25) and $\mathrm{Val}(58)$ are found in the inhibitors from all five species, and in the remaining 5 invariant positions in the four highly homologous inhibitors: Glu(26), Gly(29), Ala(35), $\operatorname{Arg}(66)$ and $\operatorname{Val}(67)$, the yeast inhibitor contains the following residues, respectively: Asp(26), Ala(29), Ser(35), Lys(66) and Leu(67). These observations may be of interest for future studies of the structure, mechanism and specificity of all the inhibitors.

The high degree of homology often found in the active site region of otherwise unrelated inhibitors belonging to different families has, generally, been explained as the result of a convergent evolution (10). When sequences around the reactive site of the four inhibitors from the "potato inhibitor I family" are compared with those of other inhibitors, many similarities are found, especially with animal inhibitors of the "Kazal pancreatic secretory trypsin inhibitor family « and microbial inhibitors of the related "Streptomyces subtilisin inhibitor family « (Table III). Almost all inhibitors sequenced within these families have Thr or Pro in the $\mathrm{P}_{2}$ position and Pro in the $\mathrm{P}_{4}$ ' position. Asx or Glx appear with high frequencies in the $\mathrm{Pi}_{1}$, aromatic/hydrophobic amino acids in the $\mathrm{P}_{2}{ }^{\prime}$ and Arg or Asx in the $\mathrm{P}_{3}{ }^{\prime}$ position $(7,10)$. Barley inhibitor $\mathrm{CI}-2$ and potato inhibitor I have, for example, a pentapeptide in the active site $\left(\mathrm{P}_{2}-\mathrm{P}_{3}{ }^{\prime}\right)$ identical with domain 3 of pheasant ovomucoid and a domain of canine submandibular gland inhibitor, respectively, (Table III). In contrast, barley inhibitor CI- 1 has Pro in both positions $\mathrm{P}_{2}$ and $\mathrm{P}_{4}$ as the Streptomyces subtilisin inhibitor and many of the "Kazal family« inhibitors.

\section{Table III}

Comparison of reactive site sequences from different "families» of inhibitors.

Inhibitor

Amino acid sequence around reactive sites

$$
\begin{array}{llllllll}
P_{4} & P_{3} & P_{2} & P_{1} & P_{i} & P_{2}^{-} & P_{3}^{-} & P_{i}^{-}
\end{array}
$$

Met-Val-Pro-Leu-Asn-Phe-Asn-Pro

Met-Cys-Pro-Met-Va1-Tyr-Asp-Pro

Streptomyces inhibitor S-SI (10)

Canine submandibular gland inhibitor 2 (10) Met-Cys-Thr-Met-Asp-Tyr-Arg-Pro

Pheasant ovomucoid 3 (7)

Ala-Cys-Thr-Met-Glu-Tyr-Arg-Pro

Barley inhibitor CI-2 (19)

Ile-Val-Thr-Met-Glu-Tyr-Arg-Ile

Potato inhibitor I (16)

Tyr
Pro-Val-Thr-Met_-Asp-Phe-Arg-Cys
Leu Leu

Leech Eglin (17)

Pro-Val-Thr-Leu-Asp-Leu-Arg-Tyr 
It should be noted, that the four inhibitors from the "potato inhibitor I family«, as well as the yeast protease $B$ inhibitor, all have a $\mathrm{Val}$ in the $\mathrm{P}_{3}$ position. In contrast, this position is always occupied by a Cys in inhibitors from the "Kazal inhibitor«, the "Streptomyces inhibitor" and also the "Bowman-Birk Plant inhibitor» families (10).

Physiological functions of inhibitor I from potatoes and other Solanaceae plants have been intensively studied and, apparently, this inhibitor is an essential part of a defense system under hormone-like control in the vegetative plant (for references, see 3,10,20). We have now shown that the two major inhibitors of microbial proteinases and chymotrypsins present in the barley grain both are highly homologous with the Solanaceae inhibitor I. Hitherto it has not been possible to demonstrate the presence of these inhibitors, or mechanisms inducing their synthesis, in vegetative tissues of the barley plant, and further studies are necessary to elucidate their possible protective role in storage as well as in vegetative parts of barley and other cereal plants.

\section{ACKNOWLEDGEMENTS}

The skilled technical assistance of BoDIL Corneluussen and Lone Sorensen, Carlsberg Laboratory, and SusANNE JENSEN, Department of Biochemistry and Nutrition, is gratefully acknowledged. We also thank Professor MarTin OTIESEN for a critical review of the manuscript.

\section{REFERENCES}

1. BegG, G. \& F. J. Morgan: A non-volatile buffer with improved performance in automated protein sequencing. FEBS Lett. 66, 243-245 (1976)

2. Biedermann, K., U. Montali, B. Martin, $I$. SVENDSEN \& M. OtTESEN: The amino acid sequence of proteinase $A$ inhibitor 3 from baker's yeast. Carlsberg Res. Commun. 45, 225-235 (1980)

3. Boisen, S., C. Y. Andersen \& J. HejgaArd: Inhibitors of chymotrypsin and microbial serine proteases in barley grains. Isolation, partial characterization and immunochemical relationships of multiple molecular forms. Physiol. Plant. 52, 167-176 (1981)
4. Hejgaard, J. \& S. Boisen: High-lysine proteins in Hiproly barley breeding: Identification, nutritional significance and new screening methods. Hereditas 93, 311-320 (1980)

5. HeJgaARD, J.: Isoelectric focusing of subtilisin inhibitors: Detection and partial characterization of cereal inhibitors of chymotrypsin and microbial proteases. Anal. Biochem. 116, 444-449 (1981)

6. JoNASSEN, I.: Characteristics of Hiproly barley I. Isolation and characterization of two watersoluble high-lysine proteins. Carlsberg Res. Commun. 45, 47-58 (1980)

7. Kato, I, W. J. Kohr \& M. Laskowski, Jr.: Evolution of avian ovomucoids. In: Regulatory proteolytic enzymes and their inhibitors. Proc. 11 th FEBS Meeting, Copenhagen 1977. S. Magnusson et al., eds., Pergamon Press, Oxford, pp. 197-206 (1978)

8. Kominami, E., H. Hoffschulte, L. Leuschel, K. MAIER \& H. Holzer: The substrate specificity of proteinase B from baker's yeast. Biochim. Biophys. Acta 661, 136-141 (1981)

9. KulbE, K. D.: Micropolyamide thin-layer chromatography of phenyl-thiohydantoin amino acids (PTH) at a subnanomolar level. Anal. Biochem. 59, 564-573 (1974)

10. Laskowski, M. Jr., \& I. Kato: Protein inhibitors of proteinases. Ann. Rev. Biochem. 49, 593-626 (1980)

11. Maier, K., H. Müller, R. Tesch, I. Witt \& H. HolzER: Amino acid sequence of yeast proteinase B inhibitor 1. Comparison with inhibitor 2. Biochem. Biophys. Res. Commun. 91, 13901398 (1979)

12. Martin, B., I. Svendsen \& M. Ottesen: Use of carboxypeptidase $\mathrm{Y}$ for carboxy-terminal sequence determination in proteins. Carlsberg Res. Commun. 42, 99-102 (1977)

13. Mikola, J. \& E.-M. Suolinna: Purification and properties of an inhibitor of microbial alkaline proteinases from barley. Arch. Biochem. Biophys. 144, 566-575 (1971)

14. Plunkett, G. \& C. A. Ryan: Reduction and carboxamidomethylation of the single disulfide bond of proteinase inhibitor I from potato tubers. Effects on stability, immunological properties, and inhibitory activities. J. Biol. Chem. 255, 2752-2755 (1980)

15. Richardson, M. \& L. Cossins: Chymotryptic inhibitor I from potatoes: The amino acid sequences of subunits B, C, and D. FEBS Lett. 45, 11-13 (1974). (Corrigendum in FEBS Lett. $52,161(1975))$

16. RichaRdson, M., R. D. J. BarkeR, R. T. MC Millan \& L. M. Cossins: Identification of the 
reactive (inhibitory) sites of chymotryptic inhibitor I from potatoes. Phytochemistry 16,837839 (1977)

17. Seemüller, U., M. Eulitz, H. Fritz \& A. Strobl: Structure of the Elastase-Cathepsin G inhibitor of the leech Hirudo medicinalis. HoppeSeyler's Z. Physiol. Chem. 361, 1841-1846 (1980)

18. Seemüller, U., H. Fritz \& M. Eulutz: Eglin: Elastase-Cathepsin $G$ inhibitor from leeches. Methods in Enzymology 80, 804-816 (1981)
19. Suendsen, I., B. Martin \& I. Jonassen: Characteristics of Hiproly barley. III. Amino acid sequences of two lysine-rich proteins. Carlsberg Res. Commun. 45, 79-85 (1980)

20. Svendsen, I., I. Jonassen, J. Hejgaard \& S BoISEN: Amino acid sequence homology between a serine protease inhibitor from barley and potato inhibitor I. Carlsberg Res. Commun. 45, 389-395 (1980) 